\title{
The apoptosis regulators p53, bax and PUMA: Relationship and impact on outcome in early stage (FIGO I-II) ovarian carcinoma after post-surgical taxane-based treatment
}

\author{
I. SKÍRNISDÓTTIR ${ }^{1}$ and T. SEIDAL ${ }^{2}$ \\ ${ }^{1}$ Department of Women's and Children's Health, Obstetrics and Gynecology, Uppsala University Hospital, Uppsala; \\ ${ }^{2}$ Department of Pathology, Halmstad Medical Central Hospital, Halmstad, Sweden
}

Received October 21, 2011; Accepted November 18, 2011

DOI: $10.3892 /$ or.2011.1578

\begin{abstract}
The objective of this study was to evaluate the prognostic effect of the apoptosis regulators p53, bax and PUMA for recurrent disease and disease-free survival (DFS) in a series of 105 patients in FIGO-stages I-II with epithelial ovarian cancer, all treated with post-surgical platinum-taxane chemotherapy. For the detection of positivity of the biological markers p53, bax and PUMA the techniques of tissue microarrays and immunohistochemistry (IHC) were used. In tumors the frequency of $\mathrm{p} 53$ positivity was $24 \%$, that of bax positivity was $83 \%$, and strong positivity was found for PUMA (43\%). The bax status was related to tumor grade $(\mathrm{P}=0.029)$. Positive staining for bax was related to strong positivity of PUMA in the tumors $(\mathrm{P}=0.004)$. The $\mathrm{p53}$, bax or PUMA status alone or concomitant (p53 bax, p53 PUMA and bax PUMA) were not related to age, histopathological subtype, serous/non-serous tumors or type of the staging procedure at primary surgery. In survival analysis p53-positive tumors $(\mathrm{P}=0.014)$ and concomitant p53-positive and weak PUMA-positive tumors $(\mathrm{P}=0.015)$ were significantly correlated with shorter DFS. Concomitant p53-negative and bax-positive tumors were significantly correlated with longer survival $(\mathrm{P}=0.019)$. FIGO-stage $(\mathrm{OR}=6.0)$ and p53 status $(\mathrm{OR}=4.1)$ were predictive factors for tumor recurrence in logistic regression analysis and independent prognostic factors ( $\mathrm{HR}=2.4$ for both) in multivariate Cox regression analysis. In a separate Cox multivariate regression analysis the p53 bax status $(\mathrm{HR}=2.2)$ was an independent prognostic factor for DFS. The p53 PUMA status $(\mathrm{HR}=0.4)$ was not an independent prognostic factor, however, a borderline significance $(\mathrm{P}=0.07)$ was noted. Our results indicate that FIGO stage and p53 status alone were independent predictive factors for recurrence and prognostic factors for survival.
\end{abstract}

Correspondence to: Dr Ingirídur Skírnisdóttir, Department of Women's and Children's Health, Department of Obstetrics and Gynecology, Uppsala University Hospital, Akademiska Sjukhuset, SE-751 85 Uppsala, Sweden

E-mail: ingiridur.skirnisdottir@kbh.uu.se

Key words: p53, bax, PUMA, ovarian cancer, prognostic markers
Furthermore, p53 bax status was an independent prognostic factor for survival in this study.

\section{Introduction}

Epithelial ovarian cancer is still the leading cause of mortality among women with gynecologic malignancies. Nearly $30 \%$ of the patients will present with stage I-II disease with the favorable 5-year survival being 70-90\%. However, nearly one-third of patients initially diagnosed with early-stage ovarian cancer will recur (1-3). Primary surgery with comprehensive surgical staging is the cornerstone of treatment for all epithelial ovarian cancer followed by platinum- and taxane-based chemotherapy $(4,5)$. Clinicopathological parameters have been proven insufficient to define prognostic subgroups and to predict response to chemotherapy (6).

Nowadays, it is accepted that cancer can arise as a cell cycle defect, where injured or mutated cells are allowed to progress through the cell cycle $(7,8)$. Apoptosis, a goal of cancer treatment is controlled by regulators, which have either an inhibitory effect on programmed cell death or block the protective effect of inhibitors $(9,10)$. The tumor suppressor gene p53 and its protein p53, has a crucial function as an apoptosis regulator (11). As a transcription factor, wild-type p53 can limit cell proliferation after DNA damage by arresting the cell cycle or inducing apoptosis by activating the expression of bax, PUMA and other apoptosis regulators $(11,12)$. The mitochondrial pathway plays an essential role in apoptosis induction and is controlled by the bcl-2 family of anti-apoptotic proteins and the pro-apoptotic proteins bax and PUMA (BH3-only protein) (13). Positive staining for p53 has been associated with worse survival rates $(14,15)$ and high bax expression was a favourable prognostic factor in two studies $(6,16)$. PUMA was shown to be an independent predictor of overall survival in a study on patients with colorectal cancer (17). As survival after recurrence in stage I-II ovarian cancer is comparable to those with recurrent advanced-stage disease (1), identification of new prognostic factors to improve treatment is necessary. The present study was undertaken to evaluate the prognostic effect of the apoptosis regulators p53, bax and PUMA in a series of 105 patients in FIGO-stages I-II with epithelial ovarian cancer, all treated with post-surgical platinum-taxane chemotherapy. 


\section{Materials and methods}

Patients and treatment. This study assessed 105 patients in FIGO-stages I-II epithelial ovarian cancer, who were a part of a patient population of 131 patients in earlier published studies $(18,19)$. The study was approved by the local Ethics Committee (decision ref. UPS-03-477). All patients underwent primary surgery and postoperative adjuvant taxane carboplatin chemotherapy and were recruited in the Uppsala-Örebro Medical region between January 2000 and December 2004. Adequate (optimal or modified) surgical staging according to the EORTC surgical staging categories in early ovarian cancer (20) was undertaken in $33(31 \%)$ out of the 105 cases, and in the remaining $72(69 \%)$ patients surgical staging was regarded as inadequate according the same guidelines. Patients' characteristics are demonstrated in Table I. All patients in the study received paclitaxel $175 \mathrm{mg} / \mathrm{m}^{2}$ and carboplatin $(\mathrm{AUC}=5)$ at 3-week intervals, usually in 4-6 courses 4-6 weeks after primary surgery. The mean follow-up time was 67 months (range 9-110 months).

Clinical sampling and tissue microarray construction of ovarian cancer tissue. Tissue samples of ovarian cancers were obtained at the time of primary surgery. The tissue microarrays were constructed as described previously (21) from core tissue biopsy specimens (diameter $0.6 \mathrm{~mm}$ ). Tumor tissues were embedded in paraffin and $5 \mu \mathrm{m}$ sections stained with haematoxylin-eosin were obtained to select representative areas for biopsies. Two core biopsies were obtained from each specimen. The presence of tumour tissue on the arrayed samples was verified by the haematoxylin-eosin-stained section. The specimens were then reviewed, classified and graded by a single pathologist.

Immunohistochemistry. Five micrometer sections were cut from each multi-tissue block and were placed on coated slides and dried overnight at $37^{\circ} \mathrm{C}$. The sections were pretreated by heat-induced epitope retrieval in target-retrieval solution (Dako, Glostrup, Denmark), pH 6 or EDTA buffer pH 9, for $7+7 \mathrm{~min}$ in a microwave oven $\left(99^{\circ} \mathrm{C}\right)$. Blocking with peroxidase was performed for $5 \mathrm{~min}$. The slides were counterstained with hematoxylin for $2 \mathrm{~min}$. The following monoclonal primary antibodies were used: DO-7, directed against p53 protein (dilution 1:1,000; Dako) and PUMA- $\alpha$ that was directed against PUMA protein (dilution 1:50; Abcam, Cambridge Science, Cambridge, UK). For bax protein, polyclonal bax antibody (dilution 1:100; Dako) was used as a primary antibody.

The immunostainings were performed in an Autostainer automated machine (Dako) using the REAL EnVision detection system (Dako). The immunohistochemical analyses and interpretation were performed at the Department of Pathology, Halmstad Medical Central Hospital.

Interpretation of immunohistochemical staining. The immunohistochemical (IHC) stainings were interpreted by the two authors (IS and TS). At the time of evaluation, no information was available on the specific diagnosis and prognosis for the individual cases. A semi-quantitative analysis (22) was used and the stainings were graded as negative,,+++ and +++ for p53, bax and PUMA. The staining for p53 was considered
Table I. Patient characteristics $(\mathrm{n}=105)$.

\begin{tabular}{lc}
\hline Characteristics & $\mathrm{n}(\%)$ \\
\hline Age (median) & $58.0($ range $25-84)$ \\
WHO performance status & \\
0 & $37(90.4)$ \\
1 & $66(9.6)$ \\
FIGO-stage & \\
IA & $31(29.5)$ \\
IB & $5(4.7)$ \\
IC & $52(49.5)$ \\
II & $17(13.3)$ \\
Histopathology & \\
Serous & $42(40.0)$ \\
Mucinous & $17(16.2)$ \\
Endometrioid & $32(30.5)$ \\
Clear cell & $12(11.4)$ \\
Anaplastic & $2(1.9)$ \\
FIGO-grade & \\
Grade 1 & $29(27.6)$ \\
Grade 2 & $32(30.5)$ \\
Grade 3 & $44(40.9)$ \\
\hline
\end{tabular}

to be positive when strong and widespread granular staining of the nuclei of the tumour cells was found. Staining for bax were interpreted as positive when strong granular and punctuate staining of the cytoplasm in most of the tumour cells was shown. As completely negative staining of cytoplasm for PUMA hardly was detected in this series of patients and our findings were limited to weak or moderate/strong staining of the cytoplasm; the cut-off value was considered between + (weak positive) and ++/+++ ( strong) for statistical analyses.

Statistical analyses. The Pearson's Chi-square test was used for testing proportional differences in univariate analyses. The survival curves were generated by using the KaplanMeier technique and differences between these curves were examined by the log-rank test. All tests were two-sided and the level of statistical significance was $\mathrm{P} \leq 0.05$. The Statistica 10 $\left(\right.$ StatSoft $\left.^{\mathrm{TM}}\right)$ statistical package was used for the analyses. For multivariate analyses the logistic regression model was used with recurrence as the end point and Cox regression model was used with disease-free survival (DFS) as the endpoint.

\section{Results}

Patients. The total number of recurrences in the complete series was 29 out of 105 (28\%). Recurrent disease was significantly associated with FIGO-substages $(\mathrm{P}=0.0007)$, FIGO-grade $(\mathrm{P}=0.043)$, but not with the histopathological subtype $(\mathrm{P}=0.880)$, or serous/non-serous tumors $(\mathrm{P}=0.532)$. However, the type of staging procedure at the primary surgery reached a borderline significance $(\mathrm{P}=0.053)$. In the complete series both the 5-year DFS rate and the overall survival rate (OS) were $70 \%$. 
Table II. Tumor expression of the p53-protein, bax-protein and PUMA-protein vs. clinicopathological features $(\mathrm{n}=105)$.

\begin{tabular}{|c|c|c|c|c|c|c|}
\hline & $\begin{array}{l}\mathrm{p} 53^{+} \\
\mathrm{n}(\%)\end{array}$ & $\begin{array}{l}\mathrm{p} 53^{-} \\
\mathrm{n}(\%)\end{array}$ & $\begin{array}{l}\mathrm{bax}^{+} \\
\mathrm{n}(\%)\end{array}$ & $\begin{array}{l}\text { bax }^{-} \\
\mathrm{n}(\%)\end{array}$ & $\begin{array}{c}\mathrm{PUMA}^{++} \\
\mathrm{n}(\%)\end{array}$ & $\begin{array}{c}\mathrm{PUMA}^{+} \\
\mathrm{n}(\%)\end{array}$ \\
\hline Positivity & $25(24)$ & $80(76)$ & $84(83)$ & $20(17)$ & $45(43)$ & $59(57)$ \\
\hline \multicolumn{7}{|l|}{ Histopathology } \\
\hline Serous & $13(52)$ & $29(36)$ & $36(43)$ & $6(30)$ & $21(47)$ & $20(34)$ \\
\hline Non-serous & $12(48)$ & $51(64)$ & $48(57)$ & $14(70)$ & $24(53)$ & $39(66)$ \\
\hline P-value & \multicolumn{2}{|c|}{0.160} & \multicolumn{2}{|c|}{0.292} & \multicolumn{2}{|c|}{0.187} \\
\hline \multicolumn{7}{|l|}{ Tumor grade } \\
\hline $\mathrm{G} 1+\mathrm{G} 2$ & $13(52)$ & $47(59)$ & $52(62)$ & $7(35)$ & $28(68)$ & $82(63)$ \\
\hline G3 & $12(48)$ & $33(41)$ & $32(38)$ & $13(65)$ & $13(32)$ & $19(37)$ \\
\hline P-value & \multicolumn{2}{|c|}{0.552} & \multicolumn{2}{|c|}{0.029} & \multicolumn{2}{|c|}{0.578} \\
\hline \multicolumn{7}{|l|}{ FIGO-stage } \\
\hline IA-IB & $5(20)$ & $31(39)$ & $28(33)$ & $7(35)$ & $12(27)$ & $24(41)$ \\
\hline IC & $12(50)$ & $50(50)$ & $45(54)$ & $7(35)$ & $25(55)$ & $26(44)$ \\
\hline II & $8(24)$ & $9(11)$ & $11(13)$ & $6(30)$ & $8(18)$ & $9(15)$ \\
\hline P-value & \multicolumn{2}{|c|}{0.029} & \multicolumn{2}{|c|}{0.138} & \multicolumn{2}{|c|}{0.327} \\
\hline \multicolumn{7}{|l|}{ Disease-free survival } \\
\hline Disease-free survival & $11(44)$ & $65(81)$ & $63(75)$ & $13(65)$ & $31(69)$ & $44(75)$ \\
\hline $\begin{array}{l}\text { Dead of disease or alive } \\
\text { with recurrent disease }\end{array}$ & $14(56)$ & $15(19)$ & $21(25)$ & $7(35)$ & $14(31)$ & $15(25)$ \\
\hline P-value & \multicolumn{2}{|c|}{0.0003} & \multicolumn{2}{|c|}{0.365} & \multicolumn{2}{|c|}{0.522} \\
\hline
\end{tabular}

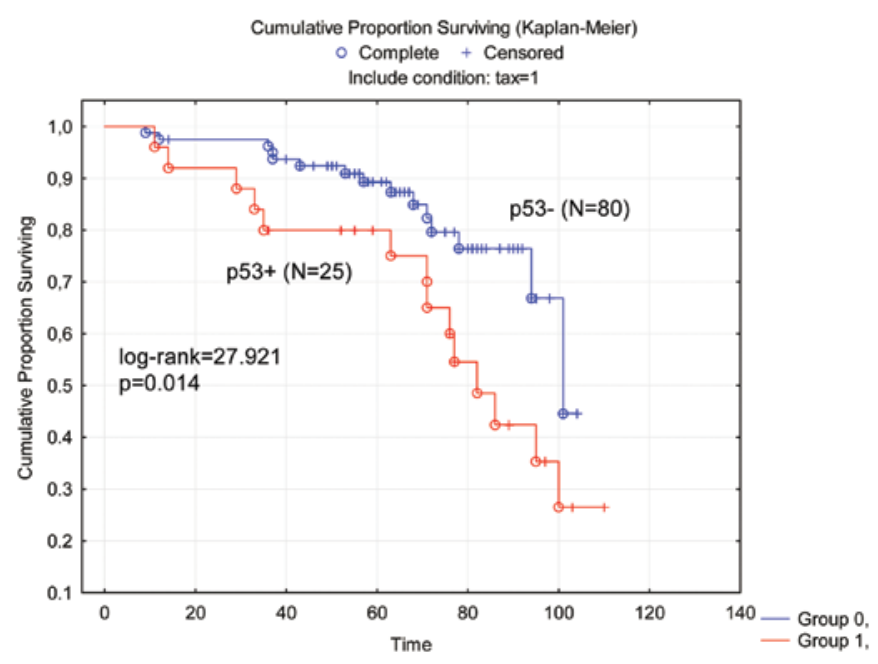

Figure 1. Kaplan-Meier plots of disease-free survival for patients demonstrated significantly $(\mathrm{P}=0.014)$ differences for patients according the $\mathrm{p} 53$ status.

Results from immunohistochemistry. Age, histopathological subtype, serous/non-serous tumors, and type of staging procedure were not related to p53, bax or PUMA status alone or combined in this study.

p53 positivity was observed in 25 out of 105 (24\%) tumors. The p53 status was significantly $(\mathrm{P}=0.029)$ associated with both FIGO-stage and disease-free survival $(\mathrm{P}=0.0003)$ (Table II). Survival analysis (Fig. 1) demonstrated a significant $(\mathrm{P}=0.014)$ difference in patients according to their p53 status. Patients with p53-negative tumors had a 5-year DFS of $90 \%$ compared to an $80 \%$ survival for patients with p53-positive tumors. Patients with p53-positive tumors continued to die after the 5-year follow-up and DFS at 100 months was only $28 \%$.

Bax positivity was observed in 84 out of 104 (83\%) available tumors. The bax status was only related to tumor grade (Table II). Thus, well- and medium-differentiated tumors (G1 and G2) usually stained bax-positive in contrast to poorly differentiated tumors (G3), that predominantly stained baxnegative $(\mathrm{P}=0.029)$. Strong positivity for PUMA was found in 45 out of 104 (43\%) available tumors. The PUMA status was not related to any of the clinicopathological features evaluated (Table II). The bax-status and the PUMA status alone were not related to survival.

Relationship between p53, bax and PUMA. The staining of $\mathrm{p} 53$ in carcinomas was not related to the staining of bax $(\mathrm{P}=0.487)$ or PUMA $(\mathrm{P}=0.140)$ in tumors. However, bax positivity was significantly $(\mathrm{P}=0.004)$ related to strong positivity of PUMA in tumors. Thus, strong positivity for PUMA was found in 42 out of the $83(51 \%)$ bax-positive tumors compared to only 3 out of the $20(15 \%)$ bax-negative tumors.

The complete series of 105 patients was split into four subgroups according to p53 and bax-status and p53 and PUMA-status of tumors, and the distribution of the subgroups were analysed according to clinicopathological features as before. It was noted that among the 65 tumors of concomitant p53 negativity and bax positivity, most (90\%) tumors were classified to sub-stages IA-IC contrary to 3 out of the $6(50 \%)$ tumours of concomitant p53 positivity and bax negativity that belonged to FIGO-stage II (Table III). Survival analysis 
Table III. Status of the p53/bax proteins vs. clinicopathological features $(n=104)$.

\begin{tabular}{|c|c|c|c|c|c|}
\hline & $\begin{array}{l}\mathrm{p} 53^{+} / \mathrm{bax}^{+} \\
\mathrm{n}(\%)\end{array}$ & $\begin{array}{l}\mathrm{p} 53^{+} / \mathrm{bax}^{-} \\
\mathrm{n}(\%)\end{array}$ & $\begin{array}{l}\mathrm{p} 53 \% \mathrm{bax}^{+} \\
\mathrm{n}(\%)\end{array}$ & $\begin{array}{l}\mathrm{p} 53 \% \mathrm{bax}^{-} \\
\mathrm{n}(\%)\end{array}$ & P-value \\
\hline Positivity & $19(18)$ & $6(7)$ & $65(62)$ & $14(13)$ & \\
\hline Histopathology & & & & & 0.107 \\
\hline Serous & $9(47)$ & $4(67)$ & $27(41)$ & $2(14)$ & \\
\hline Non-serous & $10(53)$ & $2(33)$ & $88(59)$ & $12(86)$ & \\
\hline Tumor grade & & & & & 0.092 \\
\hline $\mathrm{G} 1+\mathrm{G} 2$ & $10(53)$ & $3(50)$ & $42(65)$ & $4(36)$ & \\
\hline G3 & $9(47)$ & $3(50)$ & $23(35)$ & $10(64)$ & \\
\hline FIGO-stage & & & & & 0.025 \\
\hline IA-IB & $5(26)$ & $0(00)$ & $23(35)$ & $7(50)$ & \\
\hline $\mathrm{IC}$ & $9(47)$ & $3(50)$ & $36(55)$ & $4(29)$ & \\
\hline II & $5(27)$ & $3(50)$ & $6(10)$ & $3(21)$ & \\
\hline Disease-free survival & & & & & 0.002 \\
\hline Disease-free survival & $9(47)$ & $2(33)$ & $54(83)$ & $11(79)$ & \\
\hline $\begin{array}{l}\text { Dead of disease or alive with } \\
\text { recurrent disease }\end{array}$ & $10(53)$ & $4(67)$ & $11(17)$ & $3(21)$ & \\
\hline
\end{tabular}

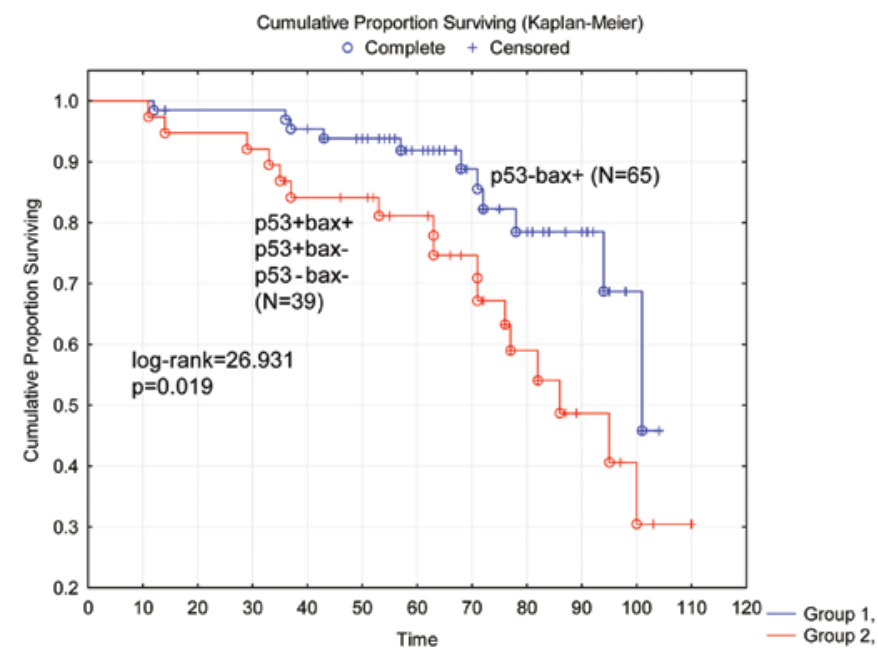

Figure 2. Kaplan-Meier plots show a significantly better $(\mathrm{P}=0.019)$ disease-

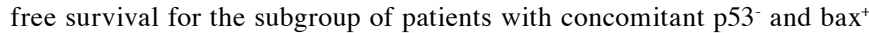
tumors compared to the other three subgroups regarded as one group $\left(\mathrm{p} 53^{+} /\right.$

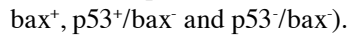

showed borderline significance $(\mathrm{P}=0.054)$ in survival (DFS) for patients in the four subgroups based on the p53-bax status. However, a separate survival analysis (Fig. 2) showed a significantly elevated $(\mathrm{P}=0.019)$ survival for the subgroup of patients with concomitant p53-negative and bax-positive tumors compared to other three subgroups regarded as one group (p53+/bax ${ }^{+}, \mathrm{p} 53^{+} / \mathrm{bax}^{-}$and $\left.\mathrm{p} 53^{-} / \mathrm{bax}^{-}\right)$. Association of the p53 PUMA status to FIGO-stage distributions reached borderline significance $(\mathrm{P}=0.056)$ (Table IV). Survival analysis for p53 PUMA status after four subgroups was not significant. However, a separate survival analysis (Fig. 3) showed significant worse $(\mathrm{P}=0.015)$ DFS for the subgroup of patients with concomitant p53-positive and weak PUMA-positive tumors

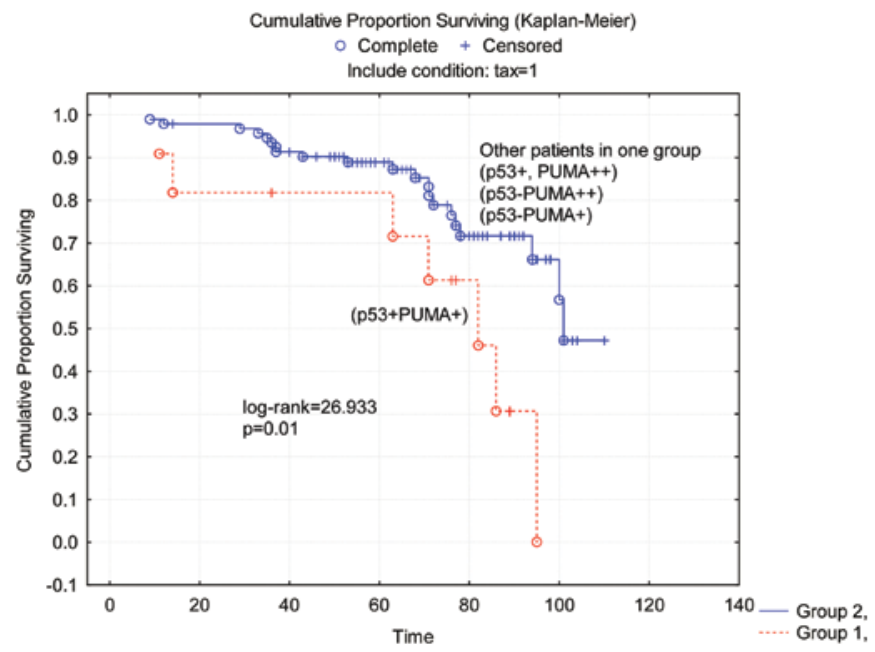

Figure 3. Kaplan-Meier plots show a significantly worse $(\mathrm{P}=0.015)$ diseasefree survival for the subgroup of patients with concomitant $\mathrm{p} 53^{+}$and weak PUMA-positive tumors compared to other three subgroups regarded as one

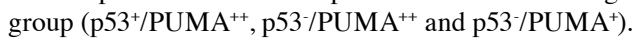

compared to other three subgroups regarded as one group $\left(\mathrm{p}^{+} / \mathrm{PUMA}^{++}, \mathrm{p} 53^{-} / \mathrm{PUMA}^{++}\right.$and p53 $/ \mathrm{PUMA}^{+}$).

Multivariate analysis. In a logistic regression analysis of predictive factors for tumor recurrences the FIGO-stage $\mathrm{OR}=6.0$ and $\mathrm{p} 53$-status $\mathrm{OR}=4.1$ were significant and independent factors (Table V).

In a multivariate Cox regression analyses with DFS as the endpoint (Table VI) FIGO-stage with the hazard ratio $(\mathrm{HR})=2.4$ and $\mathrm{p} 53$-status with $\mathrm{HR}=2.4$ were significant prognostic factors. In a separate multivariate regression analysis (Table VII) both p53 bax-status HR=2.3 and FIGO-stage $\mathrm{HR}=2.3$ were independent prognostic factors. However, the 
Table IV. Status of the p53-PUMA proteins vs. clinicopathological features $(n=104)$.

\begin{tabular}{|c|c|c|c|c|c|}
\hline & $\begin{array}{l}\mathrm{p} 53^{+} / \mathrm{PUMA}^{++} \\
\mathrm{n}(\%)\end{array}$ & $\begin{array}{l}\mathrm{p} 53^{+} / \mathrm{PUMA}^{+} \\
\mathrm{n}(\%)\end{array}$ & $\begin{array}{l}\mathrm{p} 53 / \mathrm{PUMA}^{++} \\
\mathrm{n}(\%)\end{array}$ & $\begin{array}{l}\mathrm{p} 53^{-} / \mathrm{PUMA}^{+} \\
\mathrm{n}(\%)\end{array}$ & P-value \\
\hline Positivity & $14(13)$ & $11(10)$ & $31(30)$ & $48(47)$ & \\
\hline Histopathology & & & & & 0.235 \\
\hline Serous & $7(50)$ & $6(55)$ & $14(45)$ & $14(29)$ & \\
\hline Non-serous & $7(50)$ & $5(45)$ & $17(55)$ & $34(71)$ & \\
\hline Tumor grade & & & & & 0.840 \\
\hline $\mathrm{G} 1+\mathrm{G} 2$ & $8(57)$ & $5(45)$ & $19(61)$ & $27(56)$ & \\
\hline G3 & $6(43)$ & $6(55)$ & $12(39)$ & $21(44)$ & \\
\hline FIGO-stage & & & & & 0.056 \\
\hline IA-IB & $4(29)$ & 1 (9) & $8(26)$ & $23(48)$ & \\
\hline $\mathrm{IC}$ & $6(43)$ & $6(55)$ & $19(61)$ & $20(42)$ & \\
\hline II & $4(28)$ & $4(36)$ & $12(13)$ & $5(10)$ & \\
\hline Disease-free survival & & & & & 0.003 \\
\hline Disease-free survival & $7(50)$ & $4(36)$ & $24(77)$ & $40(83)$ & \\
\hline $\begin{array}{l}\text { Dead of disease or alive with } \\
\text { recurrent disease }\end{array}$ & $7(50)$ & $7(64)$ & $7(23)$ & $8(17)$ & \\
\hline
\end{tabular}

Table V. Predictive factors for tumor recurrences (logistic regression analysis) $(n=105)$.

\begin{tabular}{lcccc}
\hline Variables & B & SE & OR & 95\% CI \\
\hline Age & 0.019 & 0.023 & 1.019 & $0.973-1.068$ \\
Stage (I vs. II) & 1.792 & 0.628 & 6.006 & $1.725-20.915$ \\
Staging $^{\text {a }}$ & -1.053 & 0.619 & 0.349 & $0.102-1.193$ \\
p53 $^{\text {b }}$ & 1.416 & 0.539 & 4.123 & $1.414-12.026$ \\
\hline
\end{tabular}

${ }^{\mathrm{a} A d e q u a t e ~ s t a g i n g ~ p e r f o r m e d / n o t ~ p e r f o r m e d ; ~}{ }^{\mathrm{b}} \mathrm{p} 53$-negative vs. positive.

Table VI. Cox proportional hazard analysis of disease-free survival rate $(n=105)$.

\begin{tabular}{|c|c|c|c|c|c|}
\hline Variable & B & SE & HR & $95 \% \mathrm{CI}$ & P-value \\
\hline Age & 0.024 & 0.019 & 1.024 & $0.987-1.063$ & 0.201 \\
\hline Stage (I vs. II) & 0.0871 & 0.398 & 2.390 & $1.093-5.223$ & 0.028 \\
\hline Tumor grade ${ }^{a}$ & 0.370 & 0.401 & 1.448 & $0.660-3.179$ & 0.355 \\
\hline $\mathrm{p} 53^{\mathrm{b}}$ & 0.894 & 0.381 & 2.447 & $1.157-5.170$ & 0.019 \\
\hline
\end{tabular}

${ }^{\mathrm{a}} \mathrm{G} 1+\mathrm{G} 2$ vs. G3 tumors; ${ }^{\mathrm{p}} \mathrm{p} 53$-negative vs. positive.

Table VII. Cox proportional hazard analysis of disease-free survival rate $(n=104)$.

\begin{tabular}{|c|c|c|c|c|c|}
\hline Variable & B & SE & HR & $95 \% \mathrm{CI}$ & P-value \\
\hline Age & 0.025 & 0.019 & 1.025 & $0.987-1.064$ & 0.190 \\
\hline Stage (I vs. II) & 0.827 & 0.399 & 2.288 & $1.045-5.006$ & 0.038 \\
\hline Tumor grade & 0.231 & 0.414 & 1.260 & $0.558-2.841$ & 0.577 \\
\hline $\mathrm{p} 53 \% / \mathrm{bax}^{+\mathrm{b}}$ & 0.812 & 0.403 & 2.254 & $1.023-4.964$ & 0.043 \\
\hline
\end{tabular}

${ }^{\mathrm{a}} \mathrm{G} 1+\mathrm{G} 2$ vs.G3 tumors; ${ }^{\mathrm{b}} \mathrm{p} 53^{-} / \mathrm{bax}^{+}$vs. others (p53+/bax $\left., \mathrm{p} 53^{+} / \mathrm{bax}^{+}, \mathrm{p} 53^{-} / \mathrm{bax}^{-}\right)$. 
p53 PUMA status (analyzed together with age, stage and tumor grade) was not an independent prognostic factor for DFS $\mathrm{HR}=0.40,95 \%$ confidence interval $(\mathrm{CI})$ 0.19-1.09; $\mathrm{P}=0.07)$.

\section{Discussion}

In the present study on patients with early-stage ovarian cancer after post-surgical taxane-platinum treatment it was possible to indentify a subgroup of patients with concomitant p53-negative and bax-positive tumors, with DFS of $92 \%$ at 5 years and $70 \%$ at 8.3 years without any relation to histological subtype or type of surgical staging. Most (62\%) patients in this study belonged to this favourable subgroup. For patients in the other three

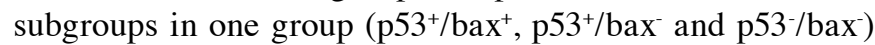
DFS was 82 and $32 \%$ at 5 years and 8.3 years, respectively. Furthermore, it was possible to indentify a subgroup of patients with concomitant p53 positivity and weak PUMA staining of tumors, with 5-year DFS of $80 \%$ and very poor outcome after a long follow-up time. On the contrary, survival for patients with p53-positive and concomitant strong PUMA-positive tumors was not different from patients with p53-negative tumors without regard to the PUMA-status of tumors. Therefore it seems that positive expression of bax or strong expression of PUMA in p53-positive tumors can protect from recurrent disease. p53-status alone was considered as the strongest prognostic biological factor in this study without any regard to different surgical staging procedures. Thus, the evaluated biomarkers in the study were not predominantly identifying missed patients with occult advanced disease, who were not adequately staged. Patients with p53-positive tumors continued to die of disease after the 5-year checkpoint and survival at 100 months from diagnosis was only $43 \%$. The risk of late recurrent disease for patients with p53 overexpression of tumors also was noted in the GOG-157 study (23). A strong correlation has been observed between a 53 mutation and DO-7 expression of the p53 protein, the antibody used in the present study $(23,24)$. The frequency of p53 positivity was $24 \%$ in this study and previous studies $(14,15,23,24)$ have reported positive staining in $20-51 \%$ of tumors belonging to patients in FIGO-stages I-II. The frequency of $83 \%$ for bax positivity in the present study could be compared with the frequency of 27 and $85 \%$, respectively from studies $(16,25)$ limited to patients in early stages or $57 \%$ in a study (26) from patients in all stages. Lack of clinical studies on ovarian cancer with regard to the BH3-only protein PUMA for comparison could be observed. PUMA expression of $91 \%$ of tumors on patients with stage II-III primary colon carcinomas (17) could be compared to strong positivity for PUMA in $43 \%$ of tumors in our study.

FIGO-stage was the strongest predictive factor for recurrent disease in this study and this has been confirmed by studies on patients in FIGO-stages I-II both after complete surgical staging $(1,27)$ and apparent staging $(5)$. However, the fact, that p53 status and p53/bax status both were independent prognostic factors for DFS in multivariate analysis was the most striking finding noted in our study. A hazard ratio (HR) of 2.5 for p53 status means 2.5 times increased risk for a patient with a p53-positive tumor to have a recurrent disease or die of disease. An HR of 1.47 for p53 status was found in a meta-analysis (28) including 62 studies with overall survival as endpoint. Furthermore, the p53-bax status with
HR of 2.2 indicated more than two times increased risk for recurrent disease or to die of disease for patients with tumors of concomitant p53-negativity and bax-positivity were moving to the other three subgroups of the p53 bax-status of tumors. In multivariate analyses a HR of 0.4 for the p53 PUMAstatus, meant a $60 \%$ reduced risk for recurrence or to die of disease for a patient with p53-negative tumors or tumors of concomitant positivity for $\mathrm{p} 53$ and strong positivity for PUMA compared to patients with tumors of p53 positivity and weak PUMA positivity.

The functional link between p53, bax and PUMA in this study could be explained by the central role of the p53 tumor suppressor protein in induction of both the cell cycle arrest and the apoptosis. In addition, the p53 protein also regulates the death effector bax activation by inducing the $\mathrm{BH} 3$-only protein PUMA in response to taxane, a microtubule-damaging agents (MDA) $(13,29)$. Bax plays an essential role in the mitochondrial pathway of apoptosis. Mitochondrial translocation of BH3-only proteins (such as PUMA) has been suggested as a critical step in bax activation during apoptosis. PUMA is essential for both p53-dependent apoptosis induced by DNA-damage and is also involved in p53-independent cell death (30-32).

The intact function of the $\mathrm{p} 53$ tumor suppressor protein in p53-negative tumors might activate the tumor suppressor bax protein in bax-positive tumors by means of a strong presence of PUMA and facilitating a taxane-mediated apoptosis that could account for the favorable prognostic effect for subgroup of patients with concomitant p53-negative and bax-positive tumors. In summary the p53 status alone and the bax p53 status were independent prognostic factors for outcome (DFS) of patients with epithelial ovarian cancer in FIGO-stages I-II after primary surgery and adjuvant platinum-taxane chemotherapy. For the first time to our knowledge, it was found, that the BH3 only protein PUMA seems to have prognostic effect on epithelial ovarian cancer in clinical studies, at least in combination with $\mathrm{p} 53$. Thus favorable prognostic effect of intact (negative) p53 status alone or combined with positive bax status or strong presence of PUMA, respectively, in tumors was observed in the present study.

\section{References}

1. Chan JK, Tian C, Teoh D, et al: Survival after recurrence in early-stage high-risk epithelial ovarian cancer: a Gynecologic Oncology Group study. Gynecol Oncol 16: 307-311, 2010.

2. Heintz AP, Odicino F, Maisonneuve P, et al: Carcinoma of the ovary. Int J Gynaecol Obstet 83: 135-166, 2003.

3. Ozols RF, Dembo AJ and Robboy S: Epithelial ovarian cancer. In: Principles and Practice of Gynecologic Oncology. Hoskins WJPC and Young RC (eds). Lippincott, Philadephia, pp731-781, 1992.

4. Jemal A, Siegel R, Ward E, et al: Cancer statistics, 2007. CA Cancer J Clin 57: 43-66, 2007.

5. Köbel M, Kalloger SE, Santos JL, Huntsman DG, Gilks CB and Swenerton KD: Tumor type and substage predict survival in stage I and II ovarian carcinoma: insights and implications. Gynecol Oncol 116: 50-56, 2010.

6. Schuyer M, van der Burg M, Henzen-Logmans SC, et al: Reduced expression is associated with poor prognosis in patients with epithelial ovarian cancer: a multifactorial analysis of TP53, p21, BAX and BCL-2. Br J Cancer 85: 1359-1367, 2001.

7. Nam EJ and Kim YT: Alteration of cell-cycle regulation in epithelial ovarian cancer. Int J Gynecol Cancer 18: 1169-1182, 2008.

8. Foster I: Cancer: a cell cycle defect. Radiography 14: 144-149, 2008. 
9. Palmer JE, Sant Cassia LJ,Irwin CJ, et al: P53 and bcl-2 assessment in serous carcinoma. J Gynecol Cancer 18: 241-248, 2008.

10. Lee DH, Kim C, Zhang L, et al: Role of p53, PUMA, and Bax in wogonin-induced apoptosis in human cancer cells. Biochem Pharmacol 75: 2020-2033, 2008.

11. Liu YY, Patwardhan GA, Bhinge K, Gupta V, Gu X and Jarwinski M: Suppression of glucosylceramide synthase restores p53-dependent apoptosis in mutant p53 cancer cells. Cancer Res 71: 2276-2285, 2011.

12. Harris SL and Levine AJ: The p53 pathway: positive and negative feedback loops. Oncogene 24: 2899-2908, 2005.

13. Yamaguchi H, Chen J, Bhalla K and Wang HG: Regulation of Bax activation and apoptotic response to microtubule-damaging agents by $\mathrm{p} 53$ transcription-dependent and independent pathways. J Biol Chem 279: 39431-39437, 2004.

14. de la Torre FJ, García A, Gil-Moreno A, et al: Apoptosis in epithelial ovarian tumours. Prognostic significance of clinical and histopathologic factors and its association with the immunohistochemical expression of apoptotic regulatory proteins (p53, bcl-2 and bax). Eur J Obstet Gynecol Reprod Biol 130: 121-128, 2007.

15. Skirnisdottir I, Sorbe B and Seidal T: A new prognostic model comprising p53, EGFR, and tumor grade in early stage epithelial ovarian carcinoma and avoiding the problem of inaccurate surgical staging. Int J Gynecol Cancer 14: 259-270, 2004.

16. Skirnisdottir I, Sorbe B and Seidal T: p53, bcl-2, bax; their relationship and effect on prognosis in early stage ovarian carcinoma. Int J Gynecol Cancer 141: 241-248, 2001.

17. Sinicrope FA, Rego RL, Okumura K, et al: Prognostic impact of Bim, Puma and Noxa expression in human colon carcinomas. Clin Cancer Res 14: 5810-5818, 2008.

18. Skirnisdottir I, Sorbe B, Lindborg K and Seidal T: Prognostic impact of p53,p27 and C-MYC on clinico-pathological features and outcome in early stage (FIGO I-II) epithelial ovarian cancer. Int J Gynecol Cancer 21: 236-244, 2011.

19. Skirnisdottir I and Seidal T: Prognostic impact of concomitant p53 and PTEN on outcome in early stage (FIGO I-II) epithelial ovarian cancer (EOC). Int J Gynecol Cancer 21: 1024-1031, 2011.

20. Trimbos JB, Vergote I, Bolis G, et al: Impact of adjuvant chemotherapy and surgical staging in early-stage ovarian carcinoma: European Organisation for Research and Treatment of CancerAdjuvant Chemotherapy in Ovarian Neoplasm trial. J Natl Cancer Inst 18: 113-125, 2003.
21. Kononen J, Bubendorf L, Kallioniemi A, et al: Tissue microarrays for high-throughput molecular profiling of tumor specimens. Nat Med 4: 844-847, 1998.

22. Seidal T, Balaton AJ and Battifora $\mathrm{H}$ : Interpretation and quantification of immunostains. Am J Surg Pathol 25: 1204-1207, 2001.

23. Darcy KM, Brady WE, McBroom JW, et al: Associations between p53 overexpression and multiple measures of clinical outcome in high-risk, early stage or suboptimally-resected, advanced stage epithelian ovarian cancers: a Gynecologic Oncology Group study. Gynecol Oncol 111: 478-495, 2008.

24. Lassus H, Leminen A, Lundin J, Lehtovirta P and Butzow R: Distinct subtypes of serous ovarian carcinoma identified by $\mathrm{p} 53$ determination. Gynecol Oncol 91: 504-512, 2003.

25. Skirnisdottir I, Seidal T, Gerdin E and Sorbe B: The prognostic importance of $\mathrm{p53}$, bcl-2, and bax in early stage epithelial ovarian carcinoma treated with adjuvant chemotherapy. Int J Gynecol Cancer 12: 265-276, 2002.

26. de la Torre J, Gil-Moreno A, García A, et al: Expression of DNA damage checkpoint protein Hus 1 in epithelial ovarian tumors correlates wit prognostic markers. Int J Gynecol Patholog 27: 24-32, 2008

27. Chan JK, Tian C, Monk BJ, et al: Prognostic factors for high-risk early-stage epithelial ovarian cancer. Cancer 112: 2202-2210, 2008.

28. de Graeff P, Crinjs APG, de Jong S, et al: Modest effect of p53, EGFR and HER-2/neu on prognosis in epithelian ovarian cancer: a meta-analysis. Br J Cancer 101: 149-159, 2009.

29. Vogelstein B, Lane D and Levine AJ: Surfing the p53 network. Nature 408: 307-310, 2000

30. Johnstone RW, Ruefli AA and Lowe SW: Apoptosis: a link between cancer genetics and chemotherapy. Cell 108: 153-164, 2002.

31. Fei P and El-Dairy WS: P53 and radiation responses. Oncogene 22: 5774-5783, 2003.

32. Wang $\mathrm{P}, \mathrm{Yu} \mathrm{J}$ and Zhang $\mathrm{L}$ : The nuclear function of $\mathrm{p} 53$ is required for PUMA-mediated apoptosis induced by DNA damage. Proc Natl Acad Sci USA 104: 4054-4059, 2007. 